\title{
The inquiry model of medicine
}

\author{
Cite as: CMAJ 2019 January 28;191:E105-6. doi: 10.1503/cmaj.180508
}

CMAJ Podcasts: author interview at https://soundcloud.com/cmajpodcasts/180508-medsoc

W hat is medicine? Answering this question matters as much as knowing whether we are consulting a doctor or a quack. We recognize medicine in all societies past and present. Yet the nature of medicine differs so greatly from place to place and time to time as to make this recognition remarkable. What is it that we see in common between the sangoma's throwing of bones and the surgeon's incisions?

One obvious suggestion is a curative thesis, with 2 parts: first, that the goal of medicine is curing the sick; and second, that curing the sick is the core competence of medicine. Both parts of this thesis face objections. I believe the objections to the first part can be overcome, but not the second.

The idea that cure is the goal of medicine fits very well with some of what medicine is and does. Where cures are known, they are used; where they are not known, they are sought. Yet there are several objections. Not all medical professionals aim (only) at cure. Nurses take care of patients, but usually do not pretend to cure them; cosmetic surgeons often aim to make people look "better"; and some physicians even assist patients who wish to die. In addition, the goal of cure may be shared by some outside medicine, including well-meaning relatives without medical knowledge and scientists (without medical training) engaged in discovering new cures. Finally, modern medical labour is divided. It is hard to see how someone working in a blood analysis laboratory has the goal of curing anyone.

Despite these objections, this aspect of the curative thesis can be defended by distinguishing between goals that individuals have, or in pursuit of which medical knowledge is used, and the goal(s) that characterizes medicine in general.
There is a reason to think that medicine has such a goal, and that it is fairly summarized as "to cure disease." Individual practitioners and practices may have different goals, but it would be very hard to imagine medicine as a whole without at least some practitioners and activities directed at the goal of cure. Medicine without the activities of research science, cosmetic surgery, palliative care or assisting dying - all directed at goals other than cure - is imaginable. Indeed, medical traditions lacking each in the foregoing list exist or have existed.

By contrast, it is hard to imagine, or to find in history, a medical tradition that does not have cure as a central goal of many practitioners and practices. We would not call such a thing "medicine." This is good reason to believe that cure is a goal of medicine.
Could not there be many goals, or a "cluster" of activities bearing a "family resemblance" ? ${ }^{1}$ Not if the foregoing argument is correct. If there is no medicine without at least some connection to the goal of cure, then the goal of cure is essential to medicine, in some sense. Maybe the same argument could be mounted for another goal; I cannot prove otherwise without proving a negative.

However, medicine cannot be characterized by its goal alone. It must also have a core skill or competence, whose practice distinguishes the medical practitioner from the layperson. Otherwise, well-meaning relatives with no medical training would count as doctors when they advise their loved ones to take an early night or to drink some water.

Here the curative thesis faces an insurmountable difficulty. Viewed from a

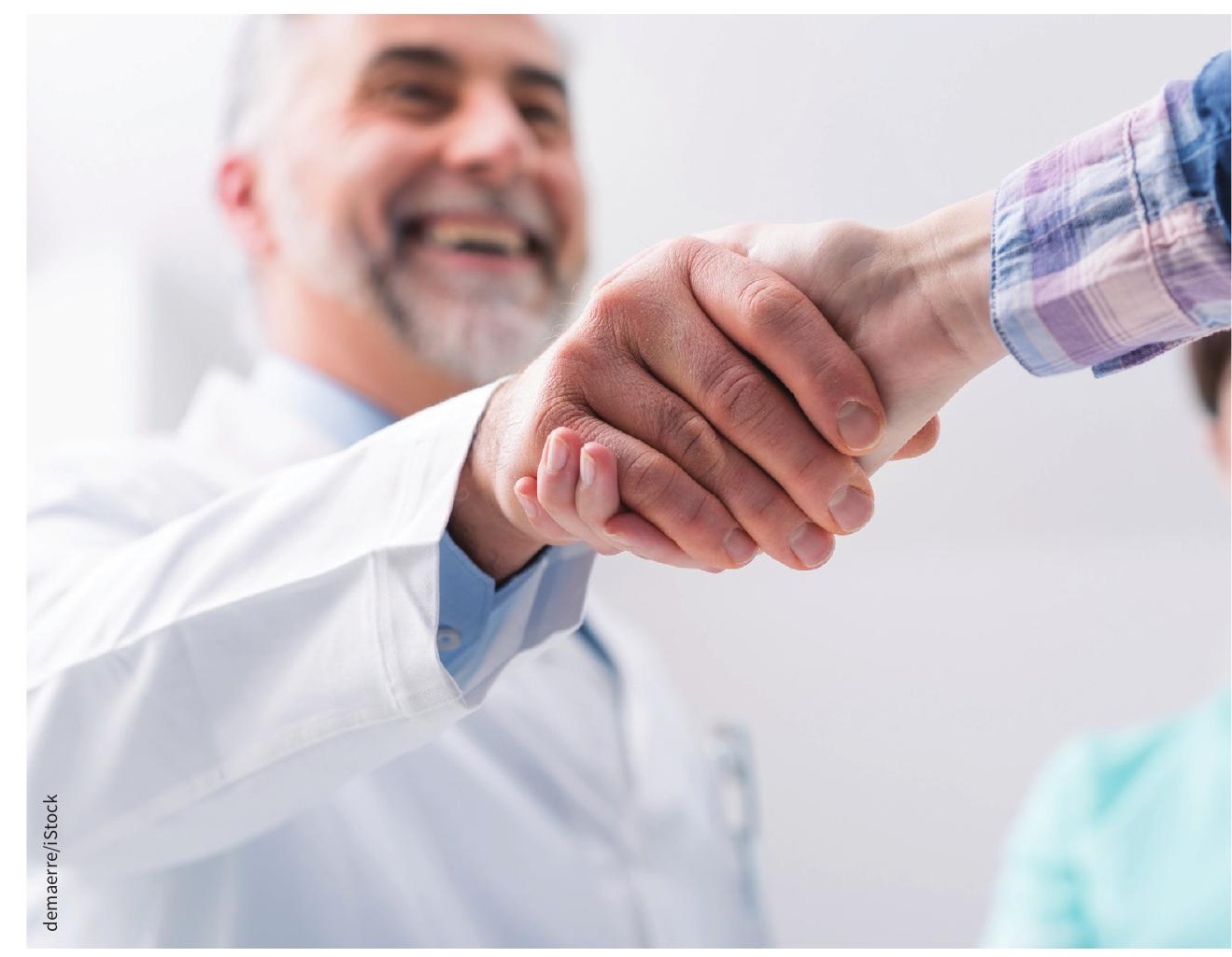


historical and global perspective, medicine is not universally or even commonly successful at obtaining cure, regardless of its intent. We do not define an activity by its goal alone, unless it has at least some success in that respect. A blacksmith cannot be defined as one who makes horseshoes if he simply throws lumps of hot metal onto his anvil and hammers them randomly, occasionally producing something horseshoelike, but more often producing a mess.

Yet, taking a historical perspective, something of this kind has been true of medicine for much of its history, before it developed a serious curative arsenal. Thus, the historian of medicine Roy Porter remarked that "the prominence of medicine has lain only in small measure in its ability to make the sick well. This was always true, and remains so today." ${ }^{2}$ Even in contemporary medicine, the successes success. Indeed, the development of Western medicine - the discovery of the circulation of the blood; function of the various organs; and function of the limbs, muscles, tendons, nerves and so forth - yielded frustratingly few curative counterparts for most of the centuries over which these developments occurred.

The inquiry thesis accepts that the goal of medicine is cure, but asserts that its core business is understanding: more fully, engaging in the project of understanding the nature and causes of health and disease.

There are several objections to the inquiry thesis, of which the following are the 3 most obvious. First, many doctors either do not (fully) understand what they treat or, if they do, do not (successfully) communicate this understanding to the patient. Who, then, understands? In what sense is the doctor's competence understanding?

\section{The inquiry thesis offers a way to understand ... medical traditions practised outside of the West, or in the West in defiance of the mainstream.}

of the psychiatrist or orthopedic surgeon or oncologist are muted compared with the wonders of penicillin, in whose glory the profession as a whole tends to clothe itself.

What, then, could be the business of medicine - the thing in which we recognize expertise, even when we accept that there is no cure to be had?

I propose that the business of medicine is understanding the nature and causes of health and disease, for the purpose of cure. I develop and defend this at greater length elsewhere, ${ }^{3-5}$ but the core of the argument is simple and can be summarized as follows.

What could medical practitioners be good at doing, that relates to the goal of cure without achieving it? The most likely candidate is understanding.

Understanding is something that we can gain without corresponding curative
The reply is to point at the expansion of "understands" to make reference to engaging in a larger project. Sometimes, the doctor understands; other times, the doctor does not understand, but puts the patient in connection with a larger project that does. In cases in which we have no understanding at all, the doctor is helpless, and unskilled in respect to this ailment. Patients hope for a cure, but they expect a diagnosis; and a doctor who cannot cure them will not necessarily be regarded as incompetent, if she can explain to the patient why cure is impossible.

Second, so-called understanding is often bogus, and we are unsuccessful in this regard as in cure. ${ }^{1,6}$ This objection, however, fails to account for the historical record, which - at least for Western medicine - is precisely a case of understanding without curative success. Moreover, just as false scientific theories have con- tributed to the development of scientific understanding (e.g., Newtonian physics), so false medical theories (e.g., humoral theory and miasma theory) have provided a foundation for what we now accept.

Third, you might object that the core competence of medicine is deceit: that it is, or often has been, a massive exercise in quackery, chicanery and trickery - a view that David Wootton appears to hold. ${ }^{7}$ But Wootton is the exception; other historians believe that many doctors have earnestly believed they were doing good. ${ }^{2,8,9}$ How do we explain the hard-won progress of medicine, if all its practitioners were after nothing more than a quick buck?

The inquiry thesis offers a way to understand the history of medicine that makes it more than a tale of quackery and gullibility. It also provides a way to understand medical traditions practised outside of the West, or in the West in defiance of the mainstream. Those medical traditions may offer, or at least engage with a project of obtaining, a kind of understanding that Western medicine cannot. The inquiry model of medicine lays the groundwork for fruitful and respectful discussions between medical traditions, yet without descending into an untenable relativism about what works.

\section{Alex Broadbent PhD}

African Centre for Epistemology and Philosophy of Science, University of Johannesburg, Johannesburg, South Africa

\section{References}

1. Metz T. Medicine without cure?: A cluster analysis of the nature of medicine. J Med Philos 2018;43:306-12.

2. Porter R. The greatest benefit to mankind: a medical history of humanity from antiquity to the present. London (UK): Harper Collins Publishers; 1997:6.

3. Broadbent A. Prediction, understanding, and medicine. J Med Philos 2018;43:289-305.

4. Broadbent A. Intellectualizing medicine: a reply to commentaries on "Prediction, understanding, and medicine." J Med Philos 2018;43:325-41.

5. Broadbent A. Philosophy of medicine. New York: Oxford University Press; 2019.

6. Harris $C$. The continuing allure of cure: a response to Alex Broadbent's "Prediction, understanding, and medicine." J Med Philos 2018;43:313-24.

7. Wootton D. Bad medicine: doctors doing harm since Hippocrates. New York: Oxford University Press; 2006.

8. Porter R. Blood and guts: a short history of medicine. London (UK): Penguin; 2002.

9. Bynum W. The history of medicine: a very short introduction. Oxford (UK): Oxford University Press; 2008

This article has been peer reviewed. 